\title{
Dependence of the Photosynthetic Quantum Yield on Phytoplankton Light Absorption: Equations for Assessing Primary Production in the Black Sea
}

\author{
T. Ya. Churilova ${ }^{1, \bowtie}$, V. V. Suslin ${ }^{2}$, H. M. Sosik ${ }^{3}$ \\ ${ }^{1}$ A.O. Kovalevsky Institute of Biology of the Southern Seas, Russian Academy of Sciences, \\ Sevastopol, Russian Federation \\ ${ }^{2}$ Marine Hydrophysical Institute of RAS, Sevastopol, Russian Federation \\ ${ }^{3}$ Woods Hole Oceanographic Institution, Woods Hole, USA \\ 凶tanya.churilova@ibss-ras.ru
}

\begin{abstract}
Purpose. Investigations were performed during a scientific cruise to characterize hydrophysical properties, chlorophyll $a$ concentration, photosynthesis-irradiance curves, spectral light absorption coefficients by phytoplankton, and spectral quantum downwelling irradiance. From these results, the dependence of the photosynthetic quantum yield upon environmental factors was studied with the purpose of adapting an algorithm developed for the Baltic Sea so that it can be applied for the Black Sea.

Methods and Results. Complex hydrophysical and biological studies were carried out at several depths within the euphotic zone. Spectral bio-optical parameters were measured in accordance with the latest NASA protocols (2018). Experiments to determine the photosynthesis-light relationship were performed under temperature and light conditions similar to those in situ. The quantum yield of photosynthesis was calculated from parameters of photosynthesis-light curves (photosynthesis efficiency, light saturation parameter) and the spectral light absorption coefficients by phytoplankton pigments. It was found out that the main photosynthetic characteristics of phytoplankton, including the maximum photosynthetic quantum yield and the fraction of phytoplankton absorption associated with photoprotective accessory pigments, varied with depth within the euphotic zone, due to phytoplankton acclimation to environment factors during the period of seasonal stratification. The relationship between the photosynthetic quantum yield and the quanta absorbed by photosynthetically active phytoplankton pigments was revealed. The results of this research made it possible to build on the approach developed for other regions and modify the equation for calculating the quantum yield to apply specifically for environmental conditions in the Black Sea.

Conclusions. For the first time, comprehensive studies carried out in the Black Sea, including measurements of the photosynthesis-light dependence, spectral light absorption coefficients by phytoplankton and spectral downwelling irradiance as a function of optical depths within the euphotic zone, made it possible to reveal the equation for calculating photosynthetic quantum yield. This new equation can be applied for calculating primary production of the Black Sea using a spectral approach, based both on the results of in situ measurements and remote sensing data.
\end{abstract}

Keywords: phytoplankton, pigments, photosynthesis, quantum yield, light absorption, photosynthesis, Black Sea

Acknowledgements: the research was carried out within the framework of the state task on theme AAAA-A19-119061190081-9 and also at partial support of the RFBR grant 18-45-920070. HMS acknowledges support of the Simons Foundation (award 561126).

For citation: Churilova, T.Ya., Suslin, V.V. and Sosik, H.M., 2021. Dependence of the Photosynthetic Quantum Yield on Phytoplankton Light Absorption: Equations for Assessing Primary Production in the Black Sea. Physical Oceanography, [e-journal] 28(1), pp. 67-77. doi:10.22449/1573-160X-2021-1-67-77

DOI: $10.22449 / 1573-160 X-2021-1-67-77$

(C) T. Ya. Churilova, V. V. Suslin, H. M. Sosik, 2021

(C) Physical Oceanography, 2021 


\section{Introduction}

Primary production of phytoplankton underlies the productivity of water bodies [1-3], and is thus critical for studies of the spatial-temporal variability of primary production. For the Black Sea, a spectral approach of primary production assessment was developed. It takes into account the spectral properties of downwelling irradiance, the efficiency of light absorption by phytoplankton and the efficiency of absorbed quanta utilization in the process of primary synthesis of organic matter [4]. In this spectral model, primary production is calculated based on two photosynthetic characteristics of phytoplankton: the spectral coefficient of light absorption by phytoplankton $\left(a_{\mathrm{ph}}(\lambda)\right)$ and the quantum yield of photosynthesis $(\varphi)$. Based on the results of multiannual research, the dependence of $a_{\mathrm{ph}}(\lambda)$ on chlorophyll $a$ concentration $(C h l-a)$ was obtained and parameterized $[5,6]$. The parameterization of the link between $a_{\mathrm{ph}}(\lambda)$ and Chl-a makes it possible to retrieve $a_{\mathrm{ph}}(\lambda)$ spectra based on routine measurements of $C h l-a$, taking into account the differences in phytoplankton absorbance capacity between seasons and layers of the photosynthetic zone in the Black Sea. For the quantum yield of photosynthesis, the quantitative relationships necessary for calculating primary production in the Black Sea have not been revealed yet [4]. An approach to estimate the quantum yield based on the spectral coefficient of light absorption by phytoplankton and spectral quantum downwelling irradiance $\left(E_{\mathrm{d}}(\lambda)\right)$ was developed for the other regions of World Ocean [7, 8]. In particular, an algorithm for assessment of the quantum yield, taking into account the influence of the main environmental factors, was developed for the Baltic Sea [8]. This algorithm can be used in models based on remote sensing data. However, the use of this approach requires modification for conditions of the Black Sea.

The aim of this paper is to study the dependence of the photosynthetic quantum yield on the quanta absorbed by phytoplankton to determine the quantitative dependence of the quantum yield on environmental conditions, which is required for calculating primary production of the Black Sea using a spectral algorithm $[4,8]$.

\section{Methods}

The results of bio-optical investigations carried out during the international expedition aboard R/V Trepang in June 1996 were used. In this expedition, the $E_{\mathrm{d}}(\lambda)$, light dependence of the photosynthetic rate, and $a_{\mathrm{ph}}(\lambda)$ were measured simultaneously at several depths within the euphotic layer. $E_{\mathrm{d}}(\lambda)$ was measured with the spectroradiometer (Biospherical Instruments Inc.) at seven wavelengths: 412.5; 443.5; 489.7; 509.3; 554.4; 665.6 and $683.7 \mathrm{~nm}$. Chl- $a$ was determined by the fluorometric method described in detail in [9].

Spectral measurements of light absorption coefficients by phytoplankton pigments were carried out according to the method from [10,11], which corresponds to NASA protocol [12]. Optical densities were measured with the double-beam spectrophotometer SPECORD M40 (Carl Zeiss Jena) from 350 to $750 \mathrm{~nm}$. The $\beta$-correction of the optical density of the particles collected on 
the filter to the values for the suspended particles was done with the equations obtained in [13]. The separation of the absorption of phytoplankton pigments $\left(a_{\mathrm{ph}}(\lambda)\right)$ from the total particulate absorption was carried out according to the method from [14].

Measurement of the light dependence of the photosynthetic rate. The rate of photosynthesis was measured by the standard radiocarbon method described in [15]. Water samples were exposed for one hour at 16 irradiance levels from 5 to $1000 \mu \mathrm{mol}$ quanta $\cdot \mathrm{m}^{-2} \cdot \mathrm{s}^{-1}$ using a custom incubator. Different irradiance levels were achieved by placing flasks at various distances from the light source a halogen lamp. In addition, light filters with a neutral spectral transmission characteristic ( $\mathrm{K}=50 \%)$ were set between the flasks. A blue filter and $5 \% \mathrm{CuSO}_{4}$ solution were placed in front of the lamp to attenuate long-wavelength radiation (over $700 \mathrm{~nm}$ ). In the experiments, the irradiance inside the flasks was measured using a quantum meter equipped with $4 \pi$ sensor - QSL-2100 Scalar PAR Irradiance Sensor (Biospherical Instruments Inc.). To describe the light dependence of photosynthesis, the following empirical equation was used [16]

$$
P=P_{\mathrm{s}}\left[1-\exp \left(\alpha \cdot I / P_{\mathrm{s}^{-}}\right)\right] \exp \left(\beta \cdot I / P_{\mathrm{s}}\right),
$$

where $P$ is the rate of photosynthesis $\left(\mathrm{mgC} \cdot \mathrm{m}^{-3} \cdot \mathrm{h}^{-1}\right)$, at photosynthetically available radiation intensity $I\left(\mu \mathrm{mol}\right.$ quanta $\left.\cdot \mathrm{m}^{-2} \cdot \mathrm{s}^{-1}\right) ; P_{s}$ is the scale multiplier $\left(\mathrm{mgC} \cdot \mathrm{m}^{-3} \cdot \mathrm{h}^{-1}\right)$; $\alpha$ is the efficiency of photosynthesis, which is equal to the tangent of the initial slope of the photosynthesis - light curve $\left(\left(\mathrm{mgC} \cdot \mathrm{m}^{-3} \cdot \mathrm{h}^{-1}\right) /\left(\mu \mathrm{mol}\right.\right.$ quanta $\left.\left.\cdot \mathrm{m}^{-2} \cdot \mathrm{s}^{-1}\right)\right)$; and $\beta$ is the photoinhibition parameter $\left(\left(\mathrm{mgC} \cdot \mathrm{m}^{-3} \cdot \mathrm{h}^{-1}\right) /\left(\mu \mathrm{mol}\right.\right.$ quanta $\left.\left.\cdot \mathrm{m}^{-2} \cdot \mathrm{s}^{-1}\right)\right)$. In the absence of inhibition $(\beta=0) P_{\mathrm{s}}$ is equal to the maximum rate of photosynthesis $\left(P_{\text {max }}\right)$. The parameter of light saturation of photosynthesis $I_{\mathrm{k}}\left(\mu \mathrm{mol}\right.$ quanta $\left.\cdot \mathrm{m}^{-2} \cdot \mathrm{s}^{-1}\right)$ was calculated as follows:

$$
I_{\mathrm{k}}=P_{\max } / \alpha,
$$

where $P_{\max }\left(\mathrm{mgC} \cdot \mathrm{m}^{-3} \cdot \mathrm{h}^{-1}\right)$ and $\alpha\left(\mathrm{mgC} \cdot \mathrm{m}^{-3} \cdot \mathrm{h}^{-1}\right) /\left(\mu \mathrm{mol}\right.$ quanta $\left.\left.\cdot \mathrm{m}^{-2} \cdot \mathrm{s}^{-1}\right)\right)$ are the main photosynthetic characteristics obtained as a result of the fitting of experimental data of the photosynthesis vs light dependence with the equation (1).

Quantum yield of photosynthesis was determined based on measurements of the photosynthesis - light dependence and the spectral coefficients of light absorption by phytoplankton pigments [2]. The quantum yield values obtained in this way are usually considered as measured due to the absence of a direct method for measuring the quantum yield of photosynthesis [2, 3]. The quantum yield values were calculated by the formula [17, p. 187; 18, p. 1288]

$$
\varphi=\varphi_{\max } \tanh \left(K_{\varphi} / I\right),
$$

where $K_{\varphi}$ is the coefficient corresponding to the light intensity at which $\varphi$ reaches its maximum values at $\left(\varphi_{\max }\right)$. Due to the fact that light saturation of the photosynthetic rate is associated with a change in the quantum yield, the coefficients $K_{\varphi}$ (3) are equal to $I_{\mathrm{k}}$ (2). As a result, in the calculations of $\varphi$ 
values (3) $I_{\mathrm{k}}$ values, calculated based on the equation (2), were used. The maximum quantum yield of photosynthesis $\left(\varphi_{\max }\right)$ was calculated according to the following formula:

$$
\varphi_{\max }=\alpha / \bar{a}_{\mathrm{ph}},
$$

where $\bar{a}_{\mathrm{ph}}$ is the efficiency of light absorption by phytoplankton pigments (wavelength weighted light absorption coefficient), equal to the number of absorbed quanta, normalized to the number of quanta of photosynthetically available radiation in the environment. $\bar{a}_{\mathrm{ph}}$ is calculated according to the following formula:

$$
\bar{a}_{\mathrm{ph}}=\frac{\int_{400}^{700} a_{\mathrm{ph}}(\lambda) \cdot Q(\lambda) d \lambda}{\int_{700}^{400} Q(\lambda) d \lambda},
$$

where $Q(\lambda)$ is the quantum irradiance in the experiment, which was calculated by the formula:

$$
Q(\lambda)=E(\lambda) \cdot F(\lambda) \cdot S(\lambda)
$$

where $E(\lambda)$ is the quantum irradiance spectrum provided by the light source; $S(\lambda)$ is the spectrum of light transmission in $5 \% \mathrm{CuSO}_{4}$ solution; and $F(\lambda)$ is the spectrum of light transmission by the blue filter.

The approach to modeling the quantum yield of photosynthesis, which does not use data on the light dependence of the photosynthetic rate, indirectly considers the influence of the main environmental factors on the quantum yield variability, namely, through the specific (per Chl-a unit) absorption of light by photosynthetically active pigments of phytoplankton [7, 8, from. 530]:

$$
\varphi(z)=\varphi_{\max } \cdot f(E, T) \cdot 0.6,
$$

where $\varphi_{\max }$ is the theoretical maximum of the quantum yield, equal to $0.125 \mathrm{~mol} \mathrm{C} \cdot(\mathrm{mol} \text { quanta)})^{-1}$ [19]; 0.6 is the coefficient proposed in [8] due to the fact that in nature the value of $\varphi_{\max }$ is lower than the theoretical maximum; $f(E, T)$ is the coefficient taking into account the effect of light and temperature on the quantum yield of photosynthesis.

$$
f(E, T)=\left[1-\exp \left(\frac{P U R_{\mathrm{psp}}^{*}}{K P U R_{\mathrm{psp}}^{*}(T)}\right)\right] \cdot \frac{K P U R_{\mathrm{psp}}^{*}(T)}{P U R_{\mathrm{psp}}^{*}},
$$


where $P U R_{\mathrm{psp}}^{*}$ is the number of quanta absorbed by photosynthetically active pigments, per Chl- $a$ unit (mol quanta $\mathrm{mg}^{-1} \cdot \mathrm{s}^{-1}$ ); $\operatorname{KPUR}_{\mathrm{psp}}^{*}(T)$ is a coefficient characterizing the temperature effect on the specific absorption of light energy by phytoplankton.

The value of $P U R_{\mathrm{psp}}^{*}$ (mol quanta $\cdot \mathrm{mg}^{-1} \cdot \mathrm{s}^{-1}$ ) was determined from the total amount of quanta absorbed by all phytoplankton pigments (PUR), then normalized to Chl-a:

$$
P U R_{\mathrm{psp}}^{*}=k_{\mathrm{psp}} \cdot \frac{P U R}{C h l-a},
$$

where $k_{\mathrm{psp}}=[(1-N P P) /(1+N P P)]$ is a coefficient reflecting the contribution of photosynthetic pigments to light absorption by all pigments and taking into account the weight fraction of photoprotective pigments in the total amount of phytoplankton pigments NPP $\left(\mathrm{g} \cdot \mathrm{g}^{-1}\right)$ and an almost two-fold excess of the specific light absorption indicators of photoprotective pigments in comparison with other pigments [20]. The NPP index was determined using its dependence on the daily average PAR value in the upper mixed layer $(U M L)-P A R_{\mathrm{uml}}$ [20]:

$$
N P P=0.0842 \cdot\left(P A R_{\mathrm{uml}}-0.7\right),
$$

where $P A R_{\mathrm{uml}}$ has the dimension $\mathrm{MJ} \cdot \mathrm{m}^{-2} \cdot$ day $^{-1}$.

The energy values of solar radiation $\left(\mathrm{MJ} \cdot \mathrm{m}^{-2} \cdot\right.$ day $\left.^{-1}\right)$ was recalculated to quantum dimension (mol quanta $\mathrm{m}^{-2} \cdot$ day $^{-1}$ ) in accordance with the mean ratio for the visible domain of radiation [19]: 1 mole of quanta $=0.24 \mathrm{MJ}$. As a result, we obtained:

$$
N P P=0.0202 \cdot\left(P A R_{\mathrm{uml}}-2.92\right) .
$$

The $P A R_{\mathrm{uml}}$ value was determined by the equation from [20, p. 1266]:

$$
P A R_{\mathrm{uml}}=P A R_{0} \cdot \frac{\left[1-\exp \left(-4.6 \cdot Z_{\left.\left.\mathrm{uml} / Z_{\mathrm{eu}}\right)\right]}\right.\right.}{4.6 \cdot Z_{\mathrm{uml}} / Z_{\mathrm{eu}}},
$$

where $P A R_{0}$ is solar radiation incident on the sea surface (shipboard measurement results); $Z_{\text {uml }}$ and $Z_{\text {eu }}$ are the $U M L$ and euphotic zone depth, respectively. $Z_{\text {eu }}$ was determined as the depth of where PAR was reduced to $1 \%$ of the $P A R_{0}$.

The number of PAR quanta absorbed at depth $z(P U R(z))$ was calculated based on $E_{\mathrm{d}}(\lambda, z)$ and $a_{\mathrm{ph}}(\lambda, z)$ by the following formula: 


$$
\operatorname{PUR}(\mathrm{z})=\int_{400}^{700} E_{\mathrm{d}}(\lambda, z) \cdot a_{\mathrm{ph}}(\lambda, z) d \lambda,
$$

where $E_{\mathrm{d}}(\lambda, z)$ and $a_{\mathrm{ph}}(\lambda, z)$ are the results of measurements at various depths $(z)$ during the expedition.

$K P U R_{\mathrm{psp}}^{*}(T)$ (equation (4)) takes into account the effect of temperature $(T)$ on the specific absorption of light by photosynthetically active pigments according to the Arrhenius's equation:

$$
\operatorname{KPUR}_{\mathrm{psp}}^{*}(T)=K P U R_{\mathrm{psp}, 0}^{*} \cdot Q_{10}^{T / 10},
$$

where $K P U R_{\mathrm{psp}, 0}^{*}$ is $K P U R_{\mathrm{psp}}^{*}$ when $T=0{ }^{\circ} \mathrm{C}$, and $Q_{10}$ is the coefficient showing the increase of $P U R_{\mathrm{psp}}^{*}$ when the temperature rises by $10{ }^{\circ} \mathrm{C}$. For the Baltic Sea, the values of the coefficients were determined [8, p. 537]: KPUR $R_{\mathrm{psp}, 0}^{*}=$ $=5.237 \cdot 10^{-7} \mathrm{~mol}$ quanta $\cdot \mathrm{mg}^{-1} \cdot \mathrm{s}^{-1}$ and $Q_{10}=2.03$.

\section{Results and Discussion}

During the study period, $Z_{\mathrm{UML}}$ was $10.0 \pm 2.5 \mathrm{~m}$ on average, and $Z_{\mathrm{eu}}$ was $34 \pm 13 \mathrm{~m}$. The light dependence of the photosynthetic rate was determined for the surface layer (optical depth 0.2) and at depths with $10 \%$ PAR level (optical depth 2.3) and with $1 \%$ PAR level (optical depth 4.6). The results have shown that the values of the maximum quantum yield of photosynthesis varied from 0.0064 to $0.047 \mathrm{~mol} \mathrm{C}$. (mol quanta) ${ }^{-1}$. The lowest values were noted in the surface layer (table 1), where the PAR value was $49 \pm 14$ mol quanta $\cdot \mathrm{m}^{-2} \cdot$ day $^{-1}$ on average. Phytoplankton acclimation to such a high level of light intensity was accompanied by a change in the photosynthetic parameters, in particular, the parameter $-I_{\mathrm{k}}$. In the surface layer, $I_{\mathrm{k}}$ varied from 250 to $740 \mu \mathrm{mol}$ quanta $\cdot \mathrm{m}^{-2} \cdot \mathrm{s}^{-1}$ and was equal to $470 \pm 170 \mu \mathrm{mol}$ quanta $\cdot \mathrm{m}^{-2} \cdot \mathrm{s}^{-1}$ on average (table). The phytoplankton existing in the lower part of the euphotic zone were characterized by lower values of $I_{\mathrm{k}}$. At optical depth of $2.3, I_{\mathrm{k}}$ varied from 60 to $200 \mu \mathrm{mol}$ quanta $\cdot \mathrm{m}^{-2} \cdot \mathrm{s}^{-1}$, averaging $120 \pm 51 \mu \mathrm{mol}$ quanta $\cdot \mathrm{m}^{-2} \cdot \mathrm{s}^{-1}$. Near the bottom of the euphotic zone (optical depth 4.6), $I_{\mathrm{k}}$ varied from 40 to $120 \mu \mathrm{mol}$ quanta $\cdot \mathrm{m}^{-2} \cdot \mathrm{s}^{-1}$ and was $60 \pm 21 \mu \mathrm{mol}$ quanta $\cdot \mathrm{m}^{-2} \cdot \mathrm{s}^{-1}$ on average. The noted $I_{\mathrm{k}}$ decrease with depth is associated with phytoplankton acclimation to a decrease in irradiance within the euphotic zone (table). This result is in good agreement with known patterns of acclimation in this photosynthetic characteristic of phytoplankton, caused by changes in conditions in the habitat - irradiance, temperature and nutrient availability [2, 21].

In the process of acclimation in pigment composition and concentration in microalgae cells and their photosynthetic capacities, light conditions are the most crucial. This is due not only to the specific effect of light [2, 3], but also to the high degree of variability of light in the environment. The light intensity changes by two 
orders of magnitude within the euphotic layer. In addition, the spectral properties of irradiance change with depth markedly [20, 22].

The maximum quantum yield of photosynthesis, calculated based on the results of experimental estimates of the photosynthesis - light dependence, varied from 0.0064 to $0.047 \mathrm{~mol} \mathrm{C} \cdot(\text { mol quanta })^{-1}$, which is consistent with variability noted in the Black Sea [23]. These $\varphi_{\max }$ values are obtained for the absorption of light by all cell pigments. In summer, especially in June, the solar insolation is maximal in annual cycle (table). Under these light conditions, the proportion of accessory pigments - photoprotectors in the pigment complex of cells increases, playing a protective role for the reaction centers of the cell photosystem, absorbing excess quanta and releasing this energy in the form of thermal or light (fluorescence) energy [2, 24, 25]. The effect of a high level of irradiance on the maximum quantum yield of photosynthesis is consistent with variability across waters of different trophic status [19].

Mean values and standard deviations (in bracket) of the following parameters: chlorophyll $a$ concentration ( $\mathrm{Chl}-\mathrm{a}, \mathrm{mg} \cdot \mathrm{m}^{-3}$ ), quantum yield of photosynthesis

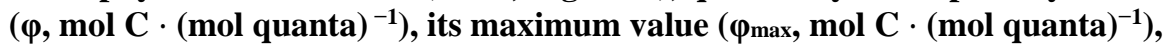

light saturation parameter $\left(I_{k}, \mu \mathrm{mol}\right.$ quanta $\left.\cdot \mathrm{m}^{-2} \cdot \mathrm{s}^{-1}\right)$, share

of photoprotective pigments (NPP, $\left.g \cdot \mathrm{g}^{-1}\right)$, daily averaged photosynthetic available radiation $\left(\overline{P A R}, \mu \mathrm{mol}\right.$ quanta $\left.\cdot \mathrm{m}^{-2} \cdot \mathrm{s}^{-1}\right)$ and daily value $\left(P A R,\left(\right.\right.$ mol quanta $\left.\cdot \mathbf{m}^{-2} \cdot \mathbf{d}^{-1}\right)$

\begin{tabular}{c|ccc|c|c|c|c}
\hline $\begin{array}{c}\text { Optical } \\
\text { depth }\end{array}$ & Chl- $a$ & $\varphi_{\max }$ & $\varphi$ & $I_{\mathrm{k}}$ & $N P P$ & $\overline{P A R}$ & $P A R$ \\
\hline & 0.36 & 0.011 & 0.0031 & 470 & 0.44 & 1500 & 49.0 \\
0.2 & $(0.17)$ & $(0.0029)$ & $(0.0010)$ & $(170)$ & $(0.17)$ & $(435.0)$ & $(14.00)$ \\
& 0.75 & 0.022 & 0.0200 & 120 & 0 & 72 & 2.3 \\
2.3 & $(0.28)$ & $(0.0076)$ & $(0.0087)$ & $(51)$ & & $(72.0)$ & $(2.40)$ \\
& 0.85 & 0.032 & 0.0320 & 60 & 0 & 12 & 0.38 \\
4.6 & $(0.43)$ & $(0.0088)$ & $(0.0088)$ & $(21)$ & & $(4.5)$ & $(0.15)$ \\
\hline
\end{tabular}

The parameter $\varphi$ varied with depth within the euphotic zone over a wide range: on average, from $0.0031 \pm 0.0010 \mathrm{~mol} \mathrm{C} \cdot(\mathrm{mol} \text { quanta })^{-1}$ near the sea surface to $0.032 \pm 0.0088 \mathrm{~mol} \mathrm{C}$ ( $(\mathrm{mol} \text { quanta) })^{-1}$ at an optical depth of 4.6 (table). Due to the fact that calculations of the quantum yield were made on the basis of results of experimental studies of the photosynthesis - light dependence (the experimental conditions were held close to the natural environment), this gives reason to consider the quantum yield values as measured in situ.

It should be noted that the process of photosynthesis involves quanta absorbed only by photosynthetically active pigments, although photoprotective pigments are present in microalgae cells and also absorb quanta. This is especially relevant for phytoplankton existing in the upper, highly illuminated layer. In this regard, it was necessary to assess the content of photoprotective pigmentsors in the planktonic microalgae. During the research period, the light intensity within the UML was $27 \pm 9.3 \mathrm{~mol}$ quanta $\cdot \mathrm{m}^{-2} \cdot$ day $^{-1}$ on average. For such light conditions, as a result of calculations (equation (5)), the NPP value in the pigment complex of phytoplankton existing in the UML, was equal to $0.44 \pm 0.17 \mathrm{~g} \cdot \mathrm{g}^{-1}$. In this case, 
the value of the $K_{\mathrm{psp}}$ coefficient was $0.41 \pm 0.18$. As a result, the light absorption only by photosynthetically active pigments was calculated.

The values of the quantum yield of photosynthesis, calculated from the results of experimental measurements of the light dependence of photosynthesis, were compared with the number of quanta absorbed by photosynthetically active pigments per unit of chlorophyll $a$ concentration $\left(P U R_{\mathrm{psp}}^{*}\right)$. As a result, a dependence between these parameters was revealed, which was described by a power function (Fig. 1).

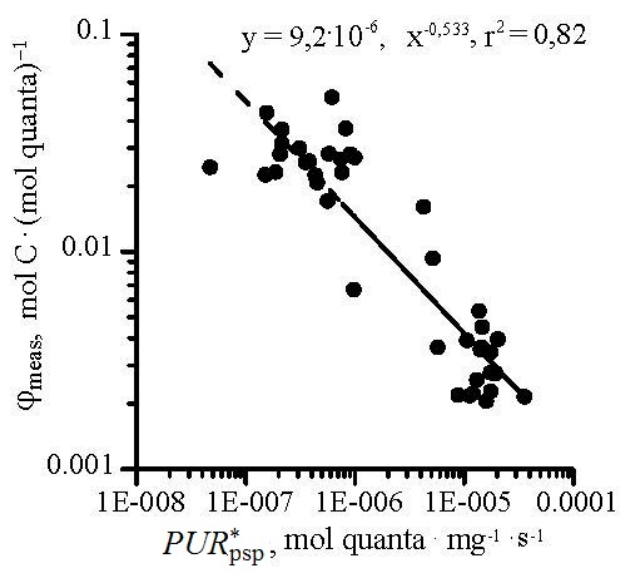

F i g. 1. Dependence of the photosynthesis quantum yield $\left.(\varphi \text {, mol C. (mol quanta })^{-1}\right)$ calculated based on the parameters of the measured photosynthesis-irradiance relationship and the spectral light absorption coefficients upon the light quanta absorbed by the photosynthetic pigments normalized on the chlorophyll a concentration ( $P U R_{\mathrm{psp}}^{*}$, mol quanta $\cdot \mathrm{mg}^{-1} \cdot \mathrm{s}^{-1}$ )

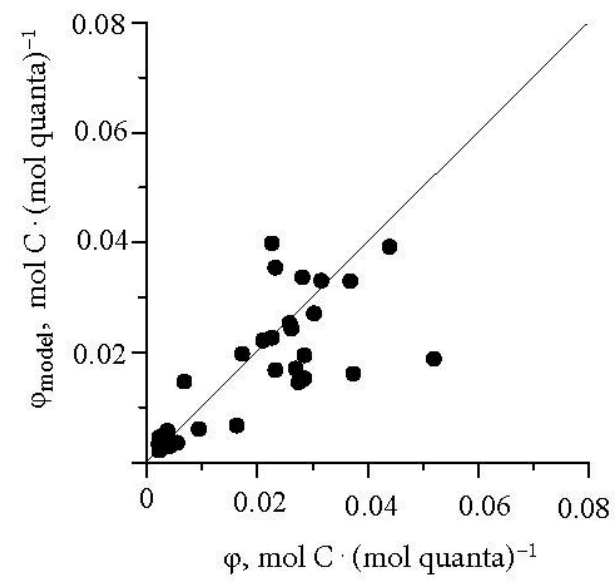

F i g. 2. Comparison of the measured quantum yield of photosynthesis $\left(\varphi\right.$, mol $\left.C \cdot(\text { mol quanta })^{-1}\right)$ with the values calculated in accordance with the approach to modeling proposed by Wozniak et al. [8] and adapted to the Black Sea environments $\left(\varphi\right.$ model, $\left.\mathrm{mol} \mathrm{C} \cdot(\text { mol quanta })^{-1}\right)$

Comparison of the measured values of the quantum yield (calculated based on the measured photosynthetic characteristics of phytoplankton) with the model results obtained in accordance with the approach [8] showed the need to change the $K P U R_{\mathrm{psp}, 0}^{*}$ coefficient (equation (6)) value for the Black Sea conditions. This approach to simulation of the quantum yield was developed based on numerous results obtained in the Atlantic Ocean [26]. For oceanic waters, it was found that the coefficient $K P U R_{\mathrm{psp}, 0}^{*}=8.545 \cdot 10^{-7} \mathrm{~mol}$ quanta $\cdot \mathrm{mg}^{-1} \cdot \mathrm{s}^{-1}[26,27]$. To calculate the quantum yield in the Baltic Sea, this coefficient value was equal to $5.237 \cdot 10^{-7} \mathrm{~mol}$ quanta $\mathrm{mg}^{-1} \cdot \mathrm{s}^{-1}$ [8]. For the Black Sea, the value of the coefficient $\left(0.99 \cdot 10^{-7} \mathrm{~mol}\right.$ quanta $\left.\cdot \mathrm{mg}^{-1} \cdot \mathrm{s}^{-1}\right)$ was obtained by comparing the measured $\varphi$ values with those calculated using the model [8], when the maximum correlation between them was achieved (the coefficient of determination $r^{2}=0.75$ ) (Fig. 2). 


\section{Conclusions}

Based on the results of the investigations that were performed during the scientific cruise and included the water hydrological properties, the chlorophyll $a$ concentration, the photosynthesis - irradiance dependences, the spectral light absorption coefficients by phytoplankton, and the spectral quantum downwelling irradiance, the influence of light conditions on the main photosynthetic characteristics of phytoplankton was shown. The dependence between the photosynthetic quantum yield and the amount of quanta absorbed by photosynthetically active pigments of phytoplankton was revealed. The equation for calculating the quantum yield in accordance with the approach developed for other water areas [8] was modified for the Black Sea. The obtained equation will be applied for calculating the primary production of the Black Sea based on the spectral approach [4].

\section{REFERENCES}

1. Geider, R.J., Delucia, E.H., Falkowski, P.G., Finzi, A.C., Grime, J.P., Grace, J., Kana, T.M., La Roche, J., Long, S.P. [et al.], 2001. Primary Productivity of Planet Earth: Biological Determinants and Physical Constraints in Terrestrial and Aquatic Habitats. Global Change Biology, 7(8), pp. 849-882. https://doi.org/10.1046/j.1365-2486.2001.00448.x

2. Falkowski, P.G. and Raven, J.A., 2007. Aquatic Photosynthesis. Princeton: Princeton University Press, 488 p. doi:10.2307/j.ctt4cgbxs

3. Williams, P.J. le B., Thomas, D.N. and Reynolds, C.S., Eds., 2002. Phytoplankton Productivity: Carbon Assimilation in Marine and Freshwater Ecosystems. Garsington: Blackwell Science Ltd, 400 p. doi:10.1002/9780470995204

4. $\quad$ Churilova, T.Ya., Suslin, V.V., Krivenko, O.V., Efimova, T.V. and Moiseeva, N.A., 2016. Spectral Approach to Assessment of Phytoplankton Photosynthesis Rate in the Black Sea Based on Satellite Information: Methodological Aspects of the Regional Model Development. Journal of Siberian Federal University. Biology, 9(4), pp. 367-384. https://doi.org/10.17516/1997-1389-2016-9-4-367-384 (in Russian).

5. Churilova, T., Suslin, V., Krivenko, O., Efimova, T., Moiseeva, N., Mukhanov, V. and Smirnova, L., 2017. Light Absorption by Phytoplankton in the Upper Mixed Layer of the Black Sea: Seasonality and Parameterization. Frontiers in Marine Science, 4, 90. https://doi.org/10.3389/fmars.2017.00090

6. Churilova, T., Suslin, V., Sosik, H.M., Efimova, T., Moiseeva, N., Moncheva, S., Mukhanov, V., Rylkova, O. and Krivenko, O., 2019. Phytoplankton Light Absorption in the Deep Chlorophyll Maximum Layer of the Black Sea. European Journal of Remote Sensing, 52(suppl. 1), pp. 123-136. https://doi.org/10.1080/22797254.2018.1533389

7. Smyth, T.J., Tilstone, G.H. and Groom, S.B., 2005. Integration of Radiative Transfer into Satellite Models of Ocean Primary Production. Journal of Geophysical Research: Oceans, 110(C10), C10014. https://doi.org/10.1029/2004JC002784

8. Woźniak, B., Ficek, D., Ostrowska, M., Majchrowski, R. and Dera, J., 2007. Quantum Yield of Photosynthesis in the Baltic: a New Mathematical Expression for Remote Sensing Applications. Oceanologia, 49(4), pp. 527-542. Available at: http://www.iopan.gda.pl/oceanologia/494wozni.pdf [Accessed: 10 January 2021].

9. Churilova, T.Y., 2001. Light Absorption by Phytoplankton and Detritus in the Black Sea in Spring. Oceanology, 41(5), pp. 687-695.

10. Yentsch, C.S., 1962. Measurement of Visible Light Absorption by Particulate Matter in the Ocean. Limnology and Oceanography, 7(2), pp. 207-217. https://doi.org/10.4319/lo.1962.7.2.0207 
11. Mitchell, B. and Kiefer, D.A., 1988. Chlorophyll a Specific Absorption and Fluorescence Excitation Spectra for Light-Limited Phytoplankton. Deep Sea Research Part A. Oceanographic Research Papers, 35(5), pp. 639-663. https://doi.org/10.1016/01980149(88)90024-6

12. Neeley, A.R. and Mannino, A., Eds., 2018. IOCCG Ocean Optics and Biogeochemistry Protocols for Satellite Ocean Colour Sensor Validation. Volume 1.0 : Inherent Optical Property Measurements and Protocols: Absorption Coefficient. Dartmouth, NS, Canada: IOCCG, 78 p. http://dx.doi.org/10.25607/OBP-119

13. Mitchell, B.G., 1990. Algorithms for Determining the Absorption Coefficient for Aquatic Particulates Using the Quantitative Filter Technique. Proceedings of SPIE: Ocean Optics X, 1302, pp. 137-148. https://doi.org/10.1117/12.21440

14. Kishino, M., Takahashi, M., Okami, N. and Ichimura, S., 1985. Estimation of the Spectral Absorption Coefficients of Phytoplankton in the Sea. Bulletin of Marine Science, 37(2), pp. 634-642.

15. Finenko, Z.Z., Churilova, T.Ya., Sosik, H.M. and Basturk, O., 2002. Variability of Photosynthetic Parameters of Surface Phytoplankton in the Black Sea. Oceanology, 42(1), pp. 53-67.

16. Platt, T., Harrison, W.G., Irwin, B., Horne, E.P. and Gallegos, C.L., 1982. Photosynthesis and Photoadaptation of Marine Phytoplankton in the Arctic. Deep Sea Research Part A. Oceanographic Research Papers, 29(10), pp. 1159-1170. https://doi.org/10.1016/01980149(82)90087-5

17. Bidigare, R.R., Prézelin, B.B. and Smith, R.C., 1992. Bio-Optical Models and the Problems of Scaling. In: P. G. Falkowski, A. D. Woodhead and K. Vivirito, Eds., 1992. Primary Productivity and Biogeochemical Cycles in the Sea. Boston, MA: Springer, pp. 175-212. https://doi.org/10.1007/978-14899-0762-2_11

18. Marra, J., Trees, C.C., Bidigare, R.R. and Barber, R.T., 2000. Pigment Absorption and Quantum Yields in the Arabian Sea. Deep Sea Research Part II: Topical Studies in Oceanography, 47(7-8), pp. 1279-1299. https://doi.org/10.1016/S0967-0645(99)00144-7

19. Kirk, J.T.O., 2011. Light and Photosynthesis in Aquatic Ecosystems. $3^{\mathrm{d}}$ ed. Cambridge: Cambridge University Press, 662 p. https://doi.org/10.1017/CBO9781139168212

20. Babin, M., Morel, A., Claustre, H., Bricaud, A., Kolber, Z. and Falkowski, P.G., 1996. Nitrogen- and Irradiance-Dependent Variations of the Maximum Quantum Yield of Carbon Fixation in Eutrophic, Mesotrophic and Oligotrophic Marine Systems. Deep-Sea Research Part I: Oceanographic Research Papers, 43(8), pp. 1241-1272. https://doi.org/10.1016/09670637(96)00058-1

21. Finenko, Z.Z., Churilova, T.Y. and Sosik, H.M., 2004. Vertical Distribution of Phytoplankton Photosynthetic Characteristics in the Black Sea. Oceanology, 44(2), pp. 205-218.

22. Churilova, T., Suslin, V., Moiseeva, N. and Efimova, T., 2018. Dissolved and Suspended Matter Variability in Coastal Waters: Photosynthetic Available Light. Proceedings of SPIE: 24th International Symposium on Atmospheric and Ocean Optics: Atmospheric Physics, 10833, 1083365. https://doi.org/10.1117/12.2504637

23. Churilova, T., Finenko, Z. and Tugrul, S., 2008. Light Absorption and Maximum Quantum Yield of Photosynthesis during Autumn Phytoplankton Bloom in the Western Black Sea. Morskoj Ehkologicheskij Zhurnal = Marine Ekological Journal, 7(3), pp. 75-86. Available at: https://repository.marine-research.org/bitstream/299011/975/1/MEJ_Churilova_et_al_2007_corrected.pdf [Accessed: 20 December 2020] (in Russian).

24. MacIntyre, H.L., Kana, T.M., Anning, T. and Geider, R.J., 2002. Photoacclimation of Photosynthesis Irradiance Response Curves and Photosynthetic Pigments in Microalgae and Cyanobacteria. Journal of Phycology, 38(1), pp. 17-38. https://doi.org/10.1046/j.15298817.2002.00094.x

25. Churilova, T.Ya., Finenko, Z.Z. and Akimov, A.I., 2008. Pigments of Microalgae. In: Yu. N.Tokarev, Z. Z. Finenko and N. V. Shadrin, Eds., 2008. The Black Sea Microalgae: Problems of Biodiversity Preservation and Biotechnological Usage. Sevastopol: ECOSI- 
Gidrofizika, pp. 301-319. Available at: http://repository.marineresearch.org/handle/299011/5521 [Accessed: 20 December 2020] (in Russian).

26. Woźniak, B., Dera, J., Ficek, D., Ostrowska, M. and Majchrowski, R., 2002. Dependence of the Photosynthesis Quantum Yield in Oceans on Environmental Factors. Oceanologia, 44(4), pp. 439-459. Available at: https://www.iopan.pl/oceanologia/444wozni.pdf [Accessed: 20 December 2020].

27. Ficek, D., 2001. Modelling the Quantum Yield of Photosynthesis in Various Marine Systems. Sopot: Institute of Oceanology PAS, 224 p.

About the authors:

Tatiana Ya. Churilova, Senior Scientist, Head of Geomatics Research Center, A.O. Kovalevsky Institute of Biology of the Southern Seas, Russian Academy of Sciences (2 Nakhimov Ave., Sevastopol, 299011, Russian Federation), Ph. D. (Biol.), ORCID ID: 0000-0002-0045-7284, Scopus Author ID: 6603622802, ResearcherID: O-8437-2016, Author ID: 888565 SPIN-код: 2238-9533, tanya.churilova@ibss-ras.ru

Vyacheslav V. Suslin, Senior Scientist, Ph. D. (Math.-Phys.), Head of the Department of the Dynamics of the Ocean Processes, Marine Hydrophysical Institute of RAS (2 Kapitanskaya St., Sevastopol, 299011, Russia), ORCID ID: 0000-0002-8627-7603, Scopus Author ID: 6603566261, ResearcherID: B-4994-2017, AuthorID: 825673 SPIN-код: 1681-7926, slava.suslin@mhi-ras.ru

Sosik Heidi Maria, Senior Scientist, Biology Department, Woods Hole Oceanographic Institution (266 Woods Hole Rd, MS\#32, Woods Hole, MA 02543), Ph. D. (Oceanography), ORCID ID: 0000-0002-4591-2842, Scopus Author ID: 35570113500, hsosik@whoi.edu

Contribution of the co-authors:

Tatiana Ya. Churilova - obtaining the data in the expedition, processing and analyzing of the results, writing the article text

Vyacheslav V. Suslin - processing the results of hydrooptical measurements

Sosik Heidi Maria - obtaining data in the expedition, analysis and discussion of the results

All the authors have read and approved the final manuscript.

The authors declare that they have no conflict of interest. 